\title{
Haemodynamic effects of prenalterol in patients with coronary heart disease
}

\author{
I HUTTON, R G MURRAY, R N BOYES, A P RAE, W S HILLIS \\ From the University Department of Medical Cardiology, Royal Infirmary, Glasgow; Astra Clinical \\ Research Unit, Edinburgh; and Department of Cardiology, Stobhill General Hospital, Glasgow
}

SUMMARY The haemodynamic effects of prenalterol, a new selective beta-1 adrenoreceptor agonist, have been studied in patients with coronary heart disease. The drug was administered intravenously in a dosage of 0.5 to $2.5 \mu \mathrm{g} / \mathrm{kg}$ body weight to 20 patients undergoing coronary angiography and to 10 patients with a recent myocardial infarction, who had clinical evidence of left ventricular dysfunction. Left ventricular performance was enhanced in both groups of patients-left ventricular $\mathrm{dP} / \mathrm{dt}(\mathrm{max})$ increased by 33 per cent and the systolic time intervals, pre-ejection period, and the ratio of pre-ejection period and left ventricular ejection shortened by 28 and 21 per cent, respectively. Cardiac output and stroke volume increased with no change in heart rate nor in left ventricular filling pressure. These results indicate that prenalterol enhances the contractile state of the myocardium without altering heart rate, and suggest that prenalterol could be of value in the management of patients with coronary heart disease, who have impaired left ventricular function.

The hospital mortality associated with acute myocardial infarction appears to result from pump failure which is related to the extent of myocardial necrosis. Such patients have been shown, both at angiography and at necropsy, to have triple vessel coronary artery disease and to have 45 to 50 per cent of the myocardium damaged..$^{1-3}$ Sympathomimetic amines have been used in the management of such cases and also to provide inotropic support after cardiac surgery. Noradrenaline increases cardiac contraction but produces intense peripheral and coronary arterial vasoconstriction resulting in increased myocardial oxygen consumption. ${ }^{4}$ Isoprenaline is a potent beta-adrenoreceptor agonist but increases heart rate in addition to its inotropic action. The deleterious side effects of the sympathomimetic amines have stimulated research into pharmacological compounds which can exert inotropic effects but have little chronotropic action. Dobutamine has been shown both in $\operatorname{man}^{5}$ and in the experimental animal ${ }^{6}$ to have a significant inotropic action, but in patients after open heart surgery, though an inotropic action was shown, there was a similar chonotropic effect to that of isoprenaline. ${ }^{7}$ Dopamine has been shown to be a useful inotropic agent particularly as it dilates the renal arterial circulation, but some workers have suggested that it Received for publication 21 August 1979 produces ventricular arrhythmias. Prenalterol, the laevoisomer of S-(-)-1-(4 hydroxyphenoxy)-3isopropylamino-propanol-2 hydrochloride, is a new selective beta-1 adrenoreceptor agonist which has been shown in animal pharmacological studies by Carlsson et al. ${ }^{8}$ to have little chronotropic effect. Johnsson et al. ${ }^{9}$ have reported in human volunteers that prenalterol, when administered both orally and intravenously, results in an increase in myocardial contractility and has little or no effect on heart rate.

The object of the present study was to assess the cardiovascular effects of prenalterol in patients with coronary heart disease undergoing coronary angiography and in patients with a recent myocardial infarction who had clinical evidence of left ventricular dysfunction.

\section{Patients and methods}

Twenty male patients with coronary heart disease undergoing coronary angiography were studied at the time of cardiac catheterisation. The patients were all in sinus rhythm and beta-adrenoreceptor blocking agents had been discontinued 48 hours before investigation. Those receiving cardiac glycosides were excluded from the study. Ten patients with acute myocardial infarction who were 
being treated in an intensive coronary care unit and who were considered to have clinical evidence of left ventricular dysfunction, as evidenced by tachycardia, additional heart sounds, and lung base crepitations, were also studied by non-invasive techniques, systolic time intervals, and echocardiography. The nature of the study was carefully explained to each patient and their consent was obtained. Approval for the study had also been obtained from the hospital ethical committee.

\section{HAEMODYNAMIC STUDY}

A high fidelity left ventricular pressure recording was obtained using a Millar transducer tipped catheter (PC-350). The catheter has a flat frequency response from 0 to $250 \mathrm{kHz}$. The left ventricular pressure wave form was recorded on a frequency modulation instrumentation tape recorder and subsequently analysed on a PDP- 8 computer. The computer digitised 8 seconds of recorded signal at a rate of 250 samples per second.. The rate of rise of pressure $\mathrm{dP} / \mathrm{dt}$ was then calculated between successive samples from end-diastole to peak systole, and $\mathrm{dP} / \mathrm{dt}(\max )$ and $\mathrm{dP} / \mathrm{dt}$ over simultaneously developed pressure $(\mathrm{P})$ was then determined for each beat analysed $(\mathrm{dP} / \mathrm{dt} / \mathrm{P}) .^{10}$ The results presented are the mean values of all beats within an 8 second sample. Heart rate was obtained from a continuous recording of the electrocardiogram, systemic blood pressure was measured from the Millar catheter, and cardiac output was determined using a thermodilution technique (Instrumentation Laboratories). All cardiac outputs were done in triplicate and the mean of the results was taken.

\section{Non-invasive study}

The systolic time intervals total electromechanical systole $\left(\mathrm{QS}_{2}\right)$, left ventricular ejection time (LVET), pre-ejection period (PEP), and ratio of PEP/LVET were measured from simultaneous high-speed recordings of the electrocardiogram, phonocardiograms, and carotid pulse wave tracing. ${ }^{11}$ Each interval was measured to the nearest $5 \mathrm{~ms}$, mean values of six cardiac cycles being obtained. Blood pressure was measured by sphygmomanometer. Echocardiographic measurements of the left ventricle were recorded. ${ }^{12}$ End-diastolic and then end-systolic volumes of the left ventricle were calculated and stroke volume derived. Heart rate was monitored from a continuous recording of the electrocardiogram.

\section{Experimental procedure}

In the haemodynamic study after baseline measurements prenalterol was infused intravenously in doses of 0.5 to $2.5 \mu \mathrm{g} / \mathrm{kg}$ body weight per minute. The drug was dissolved in dextrose and infused over a five to eight minute period using a calibrated infusion pump (Sage Instruments). Each patient received two intravenous infusions of prenalterol on consecutive occasions separated by approximately five minutes.

\section{Results}

\section{HAEMODYNAMIC STUDY}

The detailed results are noted in Table 1.

$\mathrm{dP} / \mathrm{dt}(\mathrm{max})$ increased to a maximum of $30 \mathrm{per}$ cent at an infusion rate of $1.5 \mu \mathrm{g} / \mathrm{kg}$ from $1788 \pm 146$ to $2393 \pm 206 \mathrm{mmHg} / \mathrm{s}(\mathrm{p}<0.01)$ and there was no further increase at higher rates of infusion. $\mathrm{dP} / \mathrm{dt} / \mathbf{P}$ increased from $78 \pm 1$ to $93 \pm 4 \mathrm{~s}^{-1}(\mathrm{p}<0.01)$. Left ventricular end-diastolic pressure did not change, $10 \pm 2$ to $9 \pm 1 \mathrm{mmHg}$. There was little change in heart rate until the maximum rate of infusion of $2 \mu \mathrm{g} / \mathrm{kg}$ per $\min$ when there was a non-significant increase from $79 \pm 5$ to $85 \pm 4$ beats $/ \mathrm{min}$. Systolic blood pressure was little altered, $133 \pm 11$ and $132 \pm 13 \mathrm{mmHg}$, but diastolic blood pressure fell from $81 \pm 5$ to $76 \pm 6 \mathrm{mmHg}$. Cardiac output increased from $5 \cdot 2 \pm 0 \cdot 4$ to $6 \cdot 1 \pm 0.41 / \mathrm{min}(\mathrm{p}<0.05)$. There was a corresponding increase in stroke volume from $72 \pm 11$ to $79 \pm 10 \mathrm{ml}(\mathrm{p}<0.05)$.

\section{MYOCARDIAL INFARCTION STUDY}

The detailed results are found in Table 2.

In this group of patients there was little change in heart rate until the maximum rate of infusion of $2.5 \mu \mathrm{g} / \mathrm{kg}$ per min from $83 \pm 8$ to $95 \pm 5$ beats $/ \mathrm{min}$. The pre-ejection period (PEP) significantly shortened from $114 \pm 10$ to $91 \pm 7 \mathrm{~ms}$, representing a 20 per cent increase in myocardial contractility at an infusion rate of $2 \mu \mathrm{g} / \mathrm{kg}$ per min, when there was no change in heart rate. Left ventricular enddiastolic volume was unaltered, $90 \pm 8$ and $97 \pm 6 \mathrm{ml}$, as was mean arterial blood pressure, $98 \pm 7$ and $97 \pm 7 \mathrm{mmHg}$.

A linear relation between the increases in $\mathrm{dP} / \mathrm{dt}$ and PEP/LVET and the log of plasma concentrations of prenalterol was not apparent (Fig.). Significant enhancement of myocardial contractility was found with plasma levels of 40 to $50 \mathrm{mmol} / 1$ and there was little further effect with increasing plasma levels. Plasma concentrations of prenalterol were assayed in the research laboratories of $\mathrm{AB}$ Hässle, Gothenburg, Sweden.

\section{SIDE EFFECTS}

There were no obvious side effects, specifically no adverse biochemical effects or evidence of hepatic or renal impairment. 
Table 1 Haemodynamic study

\begin{tabular}{|c|c|c|c|c|c|c|c|c|c|}
\hline Dosage regimen & $\begin{array}{l}\text { Heart rate } \\
\text { (beats } / \text { min) }\end{array}$ & $\begin{array}{l}\text { Systolic } \\
\text { BP } \\
(\mathrm{mmHg})\end{array}$ & $\begin{array}{l}\text { Diastolic } \\
B P \\
(m m H g)\end{array}$ & $\begin{array}{l}\text { Mean } \\
B P \\
(m m H g)\end{array}$ & $\begin{array}{l}\text { Cardiac } \\
\text { output } \\
(l / \text { min })\end{array}$ & $\begin{array}{l}\text { Stroke } \\
\text { volume } \\
(\mathrm{ml})\end{array}$ & $\begin{array}{l}d P / d t(\max ) \\
(m m H g / s)\end{array}$ & $\underset{\left(s^{-1}\right)}{d P / d t / P}$ & $\begin{array}{l}\text { LVEDP } \\
(m m H g)\end{array}$ \\
\hline \multirow{2}{*}{$\begin{array}{l}\text { Control } \\
0.5 \mu \mathrm{g} / \mathrm{kg} \text { body weight } \\
\text { per } \min \mathrm{n}=7\end{array}$} & $64 \pm 4$ & $134 \pm 3$ & $80 \pm 2$ & $96 \pm 4$ & $5 \cdot 8 \pm 0 \cdot 2$ & $100 \pm 6$ & $1649 \pm 132$ & $32 \pm 2$ & $10 \pm 2$ \\
\hline & $65 \pm 3$ & $136 \pm 3$ & $77 \pm 2$ & $95 \pm 5$ & $6 \cdot 2 \pm 0.1$ & $108 \pm 5$ & $1993 \pm 205^{\star}$ & $39 \pm 4^{\star}$ & $9 \pm 3$ \\
\hline \multirow{2}{*}{$\begin{array}{l}\text { Control } \\
1.0 \mu g / \mathrm{kg} \text { body weight } \\
\text { per } \min \mathrm{n}=8\end{array}$} & $85 \pm 3$ & $136 \pm 4$ & $81 \pm 3$ & $98 \pm 4$ & - & & $1949 \pm 142$ & $72 \pm 4$ & $9 \pm 3$ \\
\hline & $88 \pm 2$ & $137 \pm 5$ & $77 \pm 4$ & $96 \pm 5$ & & & $2546 \pm 187 \dagger$ & $90 \pm 6 t$ & $7 \pm 4$ \\
\hline \multirow{2}{*}{$\begin{array}{l}\text { Control } \\
1.5 \mu \mathrm{g} / \mathrm{kg} \text { body weight } \\
\text { per } \min \mathrm{n}=9\end{array}$} & $76 \pm 3$ & $133 \pm 11$ & $81 \pm 5$ & $97 \pm 6$ & $5 \cdot 2 \pm 0 \cdot 4$ & $72 \pm 11$ & $1788 \pm 146$ & $78 \pm 1$ & $10 \pm 2$ \\
\hline & $79 \pm 4$ & $132 \pm 13$ & $76 \pm 6$ & $93 \pm 7$ & $6 \cdot 1 \pm 0.4^{\star}$ & $79 \pm 10^{\star}$ & $2393 \pm 206 t$ & $93 \pm 4 \dagger$ & $9 \pm 1$ \\
\hline \multirow{2}{*}{$\begin{array}{l}\text { Control } \\
2 \cdot 0 \mu \mathrm{g} / \mathrm{kg} \text { body weight } \\
\text { per } \min \mathrm{n}=8\end{array}$} & $79 \pm 5$ & $130 \pm 15$ & $75 \pm 8$ & $92 \pm 5$ & $5 \cdot 7 \pm 0 \cdot 3$ & $75 \pm 9$ & $2145 \pm 210$ & $87 \pm 6$ & $9 \pm 1$ \\
\hline & $85 \pm 4$ & $131 \pm 17$ & $72 \pm 9$ & $90 \pm 5$ & $5 \cdot 8 \pm 0.4$ & $74 \pm 8$ & $2208 \pm 193$ & $90 \pm 5$ & $9 \pm 1$ \\
\hline
\end{tabular}

Results are mean \pm SEM. ${ }^{\star} \mathrm{p}<0.05 . \quad t \mathrm{p}<0.01$.

Table 2 Myocardial infarction study

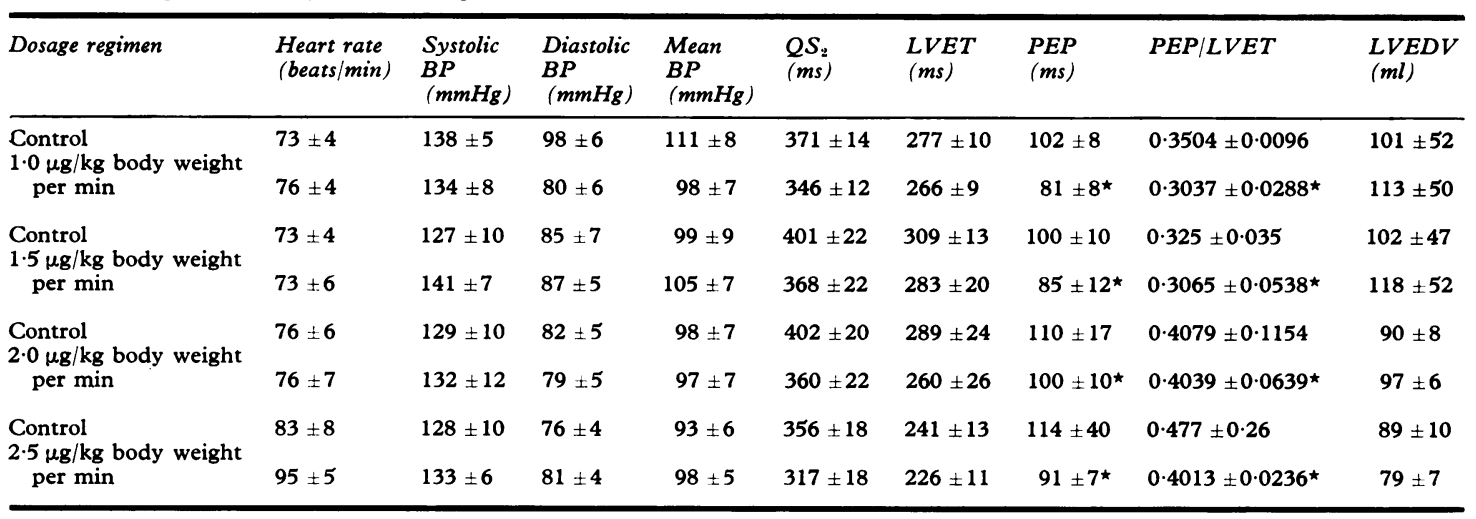

Results are mean $\pm S E M$ in 10 patients. ${ }^{\star} p<0.05$.

\section{Discussion}

The data obtained from this study suggest that prenalterol has a significant inotropic action in patients with coronary heart disease with little or no effect on heart rate. The invasive measurements of $\mathrm{dP} / \mathrm{dt}(\max )$ and $\mathrm{dP} / \mathrm{dt} / \mathrm{P}$ have been shown to be acceptable indices of myocardial contractility and to be relatively insensitive to changes in left ventricular filling pressure and ventricular afterload. ${ }^{13}$ In this study the heart rate was unaltered, left ventricular end-diastolic pressure was unchanged, as was systemic blood pressure and thus the significant increases in $\mathrm{dP} / \mathrm{dt}(\max )$ and $\mathrm{dP} / \mathrm{dt} / \mathrm{P}$ indicate that prenalterol has a positive inotropic action. This increase in the contractile state of the myocardium was also reflected by the significant increases in cardiac output and stroke volume.

Although prenalterol appears to exert a positive inotropic action in patients with coronary artery disease with normal or only modest impairment of left ventricular function, its application might be more relevant to an acute pathology such as a recent myocardial infarction. Thus it seemed appropriate to investigate the drug in patients with acute myocardial infarction, who had clinical evidence of left ventricular dysfunction. The assessment of ventricular function in these patients was by means

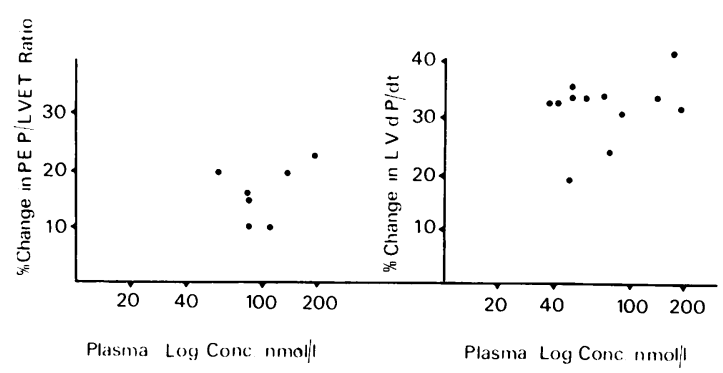

Fig. The relation between the percentage change in $d P / d t$ and pre-ejection period and the log of prenalterol plasma concentrations. 
of non-invasive techniques, systolic time intervals, and echocardiography. The duration of the preejection period in the absence of changes in preload or afterload is a determination of the rate of rise of left ventricular pressure during isovolumic contraction. ${ }^{14}$ The ratio of PEP/LVET correlates closely with the ejection fractions measured by ventriculography. ${ }^{15}$ In this study there was a significant shortening of the PEP and a decrease in PEP/LVET ratio indicating enhanced contractility. There was no change in heart rate or in systemic blood pressure. Echocardiography suggested that there was no change in left ventricular end-diastolic volume and this significant reduction in both PEP and PEP/LVET ratio indicates that prenalterol appears to enhance myocardial contractility in patients with a recent myocardial infarction, who had evidence of left ventricular dysfunction. In both groups of patients the changes in myocardial contractility did not seem to be dose related, enhancement of myocardial contractility being noted with relatively low circulating plasma levels of the drug. In patients with significant left ventricular dysfunction it may be that larger doses of prenalterol might be needed to produce a similar effect and thus increase cardiac output.

Many agents which are used to provide inotropic support are arrhythmogenic and must be used with caution in the patient with acute cardiac infarction. In this small group of patients no arrhythmias were observed despite careful electrocardiographic monitoring, and even in the presence of significantly raised plasma levels of prenalterol. These results found in patients with coronary heart disease are similar to those found in healthy patients, ${ }^{9}$ even on exercise, where arrhythmias were not found after the administration of prenalterol.

Hypotension and cardiac failure are the principal causes of death in patients with acute cardiac infarction treated in a coronary care unit, and positive inotropic agents, which are not arrhythmogenic and cause little increase in heart rate either alone or in combination with vasodilator treatment, might be of value in reducing the mortality in this group of patients. However, the greatest potential use for this beta-1 adrenoreceptor agonist with positive inotropic and little chronotropic effect appears to be in the postoperative cardiac surgical patient and in the management of patients with coronary heart disease, who have chronic congestive cardiac failure.

\section{References}

${ }^{1}$ Willerson JT, Curry GC, Watson JT, et al. Intraaortic balloon counterpulsation in patients in cardiogenic shock, medically refractory left ventricular failure and/or recurrent ventricular tachycardia. $A m \mathcal{F}$ Med 58: 183-91.

${ }^{2}$ Mathey D, Bleifeld W, Hanrath P, Effert S. Attempt to quantitate relation between cardiac function and infarct size in acute myocardial infarction. Br Heart $\mathcal{F}$ 36: 271-9.

${ }^{3}$ Wackers FJ, Lie KI, Becker AE, Durrer D, Wellens $\mathrm{HJJ}$. Coronary artery disease in patients dying from cardiogenic shock or congestive cardiac failure in the setting of acute myocardial infarction. $\mathrm{Br}$ Heart $\mathcal{F}$ 1976; 38: 906-10.

${ }^{4}$ Vatner SF, Higgins CB, Braunwald E. Effects of norepinepherine on coronary circulation and left ventricular dynamics in the conscious dog. Circ Res 1974; 34: 812-23.

${ }^{5}$ Gillespie TA, Ambos HD, Sobel BE, Roberts R. Effects of dobutamine in patients with acute myocardial infarction. Am f Cardiol 1977; 39: 588-94.

${ }^{6}$ Willerson JT, Hutton I, Watson JT, Platt MR, Templeton GH. Influence of dobutamine on regional myocardial blood flow and ventricular performance during acute and chronic myocardial ischemia in dogs. Circulation 1976; 53: 828-33.

${ }^{7}$ Kersting F, Follath R, Moulds $\mathrm{R}$ et al. A comparison of cardiovascular effects of dobutamine and isoprenaline after open heart surgery. Br Heart $\mathcal{F}$ 1976; 38: 622-6.

${ }^{8}$ Carlsson E, Dahlöf C-G, Hedberg A, Persson H, Tangstrand B. Differentiation of cardiac chronotropic and inotropic effects of beta-adrenoreceptor agonists. Naunyn Schmiedebergs Arch Pharmacol 1977; 300: 101-5.

${ }^{9}$ Johnsson G, Jordö L, Lunborg P, et al. Haemodynamic and tolerance studies in man of a new orally active selective $\beta_{1}$-adrenoreceptor agonist $\mathrm{H} \mathrm{80/62}$. Eur $\mathcal{f}$ Clin Pharmacol 1978; 13: 163-70.

${ }^{10}$ Hutton I, Hillis WS, Langhan CE, Conely JIM, Lawrie TDV. Cardiovascular effects of a new inotropic agent, U.K. 14,275 in patients with coronary heart disease. Br f Clin Pharmacol 1977; 4: 513-7.

${ }^{11}$ Weissler AM, Harris WS, Schoenfield CD. Systolic time intervals in heart failure in man. Circulation 1968; 37: 149-59.

${ }^{12}$ Feigenbaum H, Wolfe SB, Popp RL, Haine CL, Dodge, UT. Correlation of ultrasound with angiocardiography in measuring left ventricular diastolic volume (abstract). Am f Cardiol 1969; 23: 111.

${ }^{13}$ Furnival CM, Linden RJ, Snow HM. Inotropic changes in the left ventricle: the effect of changes in heart rate, aortic pressure and end-diastolic pressure. f Physiol (Lond) 1970; 211 : 359-87.

${ }^{14}$ Talley RC, Meyer JR, McNay JC. Evaluation of the pre-ejection period as an estimate of myocardial contractility in dogs. Am f Cardiol 1971; 27: 384-91.

${ }^{15}$ Garrard CL Jr, Weissler AM, Dodge HT. The relationship of alterations in systolic time intervals to ejection fraction in patients with cardiac disease. Circulation 1960 ; 42: 455-62.

Requests for reprints to Dr I Hutton, University Department of Medical Cardiology, Royal Infirmary, Glasgow G4 0SF. 